\title{
Organizational Justice and Turnover Intention among Medical and Non-Medical Workers in University Teaching Hospitals
}

\author{
Court Ogele Timinepere ${ }^{1 *}$ \\ Emmanuel K. Agbaeze ${ }^{2}$ \\ Ann Ogbo ${ }^{2}$ \\ Nwadukwe Uche C. ${ }^{3}$ \\ ${ }^{1}$ Department of Business Education, \\ Isaac Jasper Boro College of Education, \\ Sagbama, Nigeria \\ ${ }^{2}$ Department of Management, University of Nigeria, \\ Enugu Campus, Nigeria \\ ${ }^{3}$ Department of Office Technology and Management, \\ Federal Polytechnic, Oko, Nigeria \\ ${ }^{*}$ Corresponding Author
}

Doi: $10.2478 / \mathrm{mjss}-2018-0035$

\section{Abstract}

The purpose of this paper is to establish the difference in organizational justice perceptions and effects organizational justice dimensions on turnover intentions of workers in university teaching hospitals. The study adopted analytic descriptive survey design with quantitative methodology. Data were collected from university teaching hospitals in Nigeria through distribution and retrieval of 503 copies of questionnaire which was designed on a 5-point Likert scale response continuum of strongly agree to strongly disagree with corresponding weights from 5 to 1 . Data were analysed with one way analysis of variance, Duncan post hoc test and multiple regression analysis. The findings of this study demonstrated that there was a significant difference in organizational justice perception among junior, senior and management staff in teaching hospitals; there was a significant difference in organizational justice perception among medical doctors, paramedics and supporting staff in teaching hospitals; distributive justice had non-significant positive effect on turnover intention among others. There is dearth of empirical literature in organizational justice and turnover intent in teaching hospitals in the Nigerian context. This research paper bridged the knowledge gaps, demonstrated policy inadequacies in the health sector and proffered possible way forward to mitigate the incidence of industrial unrest.

Keywords: Organisational Justice, Distributive, Procedural, Interactional justice, Turnover Intention

\section{Introduction}

The health sector in Nigeria has undergone wide scale industrial actions (Osakede \& ljimakinwa, 2014; Oleribe et al, 2016) and advocacy for parity among various categories of professionals for appointment into offices at the state and federal health institutions alongside payment of emoluments and fringe entitlements( Olajide, Asuzu \& Obembe, 2015). The prime mover for the agitations is the inequality and inequity conceived among the various paramedics, physicians and supporting workforce in the health care industry in the country. To curb this trend, there is necessity for health institutions to consider the organizational justice judgments of the different group of workers to chart a policy framework for the sector. Organizational justice is the judgment of 
fairness from employees in view of the procedures leading to outcomes, allocation of resources and the interactions among workers across an entity (Wadi, 2007; Coetzee, 2005) while turnover intention designates the desire, plan and decision to leave a particular organization(Lacity et al, 2008;Perez,2008). University teaching hospitals consist of various professional groups of workers and provide health care to citizens of the nation. The medical and non-medical workers perceive organizational decisions and management actions as unfair and harbor undercurrents of resentment and anger (Greenberg, 2012; Owolabi, 2012). This undoubtedly influences the work related attitude of turnover intention. Substantial research evidence in public and private organizations corroborates relationships and effects between organizational justice and work related attitudinal variables (Lee, 2000; Oluwafemi, 2013; Nadiri \& Tanova, 2009).

A handful of studies examined the difference in organizational justice perceptions between doctors and nurses, specialty and general hospital settings among nurses. The studies provide empirical evidence to justice perceptions among these categories of health workers (Mohamend, 2014; Hatam et al, 2013,) and other sectors without comparing the different class of workers (Eves et al, 2014; Ayobami \& Eugene, 2013). The findings of the studies were inconsistent and there was insufficient research evidence to examine organizational justice at different professional groups and the levels of workers in the context of the locale of the study and the health care industry. This provides justification for the study. The objectives of this study are to establish the difference in organizational justice perceptions among junior, senior and management staff in university teaching hospitals, ascertain the difference in organizational justice perceptions among medical doctors, paramedics and supporting staff in university teaching hospitals and determine effects of organizational justice dimensions on turnover intention of workers in university teaching hospitals. These objectives guide the direction of the entire research effort. Consequently, the paper focuses on conceptual and theoretical foundations, postulation of the hypotheses, methodology, analyses and results, discussions and conclusion

\section{Conceptual and Theoretical Foundations with Postulation of Hypotheses}

\subsection{Definition of Organizational justice}

Justice is the subjective perception of workers in association with fairness in allocating outcomes, processes leading to decision outcomes and interpersonal treatment in work settings. Organizational justice focuses on descriptions and explanations of fairness in workplace (Colquitt, 2001; Greenberg, 2001). Coetzee (2005: 34) asserts that "organizational justice refers to the decisions organizations make, the procedures in making decisions and interpersonal treatment employees receive". Fairness is of principal interest to chief executive officers and managers in corporate organizations with a view to providing equal opportunities, promoting unbiased human resource practice and decisions in recruitments, performance appraisal and reward systems ((Baldwin, 2006; Bowen et al, 1999). Organizational justice revolves around three major facets of outcomes, procedures and interpersonal interactions in the workplace. These three facets form the typology of organizational justice such as distributive, procedural and interactional fairness and attracted the attention of research scholars over time (Leventhal, 1976; Thibault \& Walker, 1975; Bies \& Moag, 1986).

\subsubsection{Types of organizational Justice}

\subsubsection{Distributive justice}

This form of organizational justice is drawn from the theory of equity advocated by Adams(1965) and it is the judgment of employees in exchange relationship to be fair or unfair dependent upon the ratio of inputs and outcomes received from employer organizations, making a cognitive comparison with referents in same entity or similar organization elsewhere. The subjective judgment of employees could results in equity or inequity that lead to tension. Greenberg (2011) asserts that distributive justice centers on the belief of people who receive fair work outcomes in form of pay, recognition and other rewards. It is the perceptions of employees over equitable gains received from organizational resources, rewards and penalties ( FitzsGerald, 2002; Nirmala \& Akhilesh, 2006; Blakely et al, 2005). 


\subsubsection{Procedural justice}

Organizations specify procedures that guide managers in making decisions for the distribution of resources, promotions, transfers and performance appraisals among employees. Procedural justice therefore is a moral rule that underscores the application of fair processes to determine the distribution of outcomes to members in organizations with no modicum of bias (George \& Jones, 2006). Colquitt and Chertkoff, (2000) posit that procedural justice connotes fair and equitable practices in matters of payments, decisions and knowledge sharing and fair perception among organization members (Konovsky, 2000). Procedural justice consists of voice in decision making, consistency in applying rules, accuracy in utilizing information that guard against duplicity (Greenberg, 2011; Baldwin, 2006).

\subsubsection{Interactional justice}

Bias and Moag (1986) opine that interactional justice explains the concerns of organizational members over the equitable interpersonal treatment received in the course of implementing the procedures explicitly specified in organizations. Interactional justice comprises interpersonal interactions with truthfulness, respect and justification that emanates from procedural justice (Baldwin, 2006; Gefen et el , 2008; Karriker et el , 2009). Interactional justice presupposes that all health workers should be treated equally in their interpersonal relationship irrespective of their profession and rank in university teaching hospitals. Interactional justice has two dimensions of interpersonal and informational justice. Interpersonal justice is concerned with the manner in which people are treated with respect, dignity and politeness by decision making authorities and parties saddled with responsibility of enacting organizational procedures( Colquitt et el, 2001) while informational justice means workers' perceptions of fairness concerning information used as basis for decision making (Greenberg,2001).

\subsection{Turnover intention}

Turnover intention is an employee's desire or wish to leave his or her current organization (Lee 2002; Udechukwu et al, 2007). Furthermore, Rastgar and Pouresrahimi (2013) and Davoudi and Fartash (2013) posit that turnover intention is the conscious and deliberate willfulness of an individual towards voluntary permanent withdrawal from employer organisation. Reasons abound for employees to nurse the feeling to leave. Employees' wish and disposition to leave an employer organization arise from unfair and inequitable implementation of personnel policies and procedures for assessment of promotion and unfriendly treatment from co-workers.

From the current, extant and empirical literature reviewed, most studies concentrated on the three dimensions of organizational justice and work related attitudes while an insignificant number of studies investigated differences in organizational justice perception of workers. The contentions at different staff levels and the various medical professions in Nigeria draw our attention to examine organizational justice perceptions and turnover intentions among employees in university teaching hospitals. Thus, three major hypotheses are proposed in line with the objectives for this study.

\section{Methodology}

\subsection{Data collection procedures and sample profile}

The study adopted quantitative methodology in view of the research objectives set in this research paper. The measurement instrument has been designed and empirically validated by scholars (Colquit, 2001; Podsakoff, et el, 1990). However, minor changes were effected in the measurement scale of organizational justice which was validated using the content validity approach by giving the measure to a panel of three experts who were administrators in university teaching hospitals and two academics specializing in hospital management and administration.

The gathering of data was conducted through a sample from all staff in university teaching 
hospitals in Nigeria. A total 554 copies of questionnaire were sent out to the research subjects across the workforce of the university teaching hospitals. A total of 550 copies were returned while 47 copies were not properly filled out and discarded resulting in a sample size of 503 from a target population. To determine sample size, Cochran formula was applied through pilot survey (1963) while proportionate stratified sampling procedure was used in the selection of the sample taking into account of strata of workforce from the university teaching hospitals. Thus, the population was first subdivided into homogeneous groups (Levine et al, 2008). The application of proportionate stratified sampling was to ensure fair and adequate representation of the different categories of the workforce (Saunders et al, 2007).

\subsection{Measure of organizational Justice and Turnover intention}

The measurement instrument for the construct of organizational justice has three aspects consisting of 7 items for procedural justice, 4 items for distributive justice and 8 items for interactional justice. The scales of the construct are from previous scholars with modifications to be in proper alignment with the health sector in the Nigerian context. We adopted the Colquit, (2001) and Podsakoff, Mackerekie, Moorman and Fetter, (1990) measurement scales of organizational justice. The measure for turnover intention had 3 items (Roodt, 2004).

All the items were measured on a 5-point Likert scales ranging from strongly agree to strongly disagree with the weights of 1 to 5 respectively. In scoring the instrument, the scores for procedural justice is between the range of 7 and 35, the scores for distributive justice is between 4 and 20, the scores for interactional justice is between 8 and 40 while the scores for turnover intention is between 3 and 15(Ary, Jacobs, Razavieh \& Sorensen, 2006; Nwankwo, 2006).

\section{Analyses and Results}

To realize the set objectives and the postulated hypotheses, summary statistics of mean, standard deviation among others were presented while one way analysis of variance, Duncan pairwise test and multiple regression analysis were employed for significance test (Francis, 2004, Cooper \& Schindler, 2006). The data were analyzed using SPSS and Eviews software. The reliability of the 19 items of organizational justice measure was determined through the application of Cronbach alpha yielding a reliability index of 0.84 . The alpha coefficient of 0.84 presupposes that the instrument had high degree of internal consistency as 0.70 alpha is the criterion considered for acceptablereliability(Nunnally,1978)

4.1 $\mathrm{Ha}_{1}$ : There is a significant difference in the perception of organizational justice among junior, senior and management staff in Teaching Hospitals.

Table 1. Descriptive Statistics on the Difference in Organizational Justice Perception of Employees with Respect to Hierarchy of Workforce.

\begin{tabular}{|lcccc|}
\hline Statistics & Top $\mathbf{m g t}$ & \multicolumn{3}{c|}{ Levels of Management } \\
$\mathrm{N}$ & 20 & 231 & Junior Staff & Total \\
$\mathrm{N}$ & 55.10 & 60.66 & 252 & $\mathbf{5 0 3}$ \\
Mean & 20.47 & 16.84 & 52.31 & $\mathbf{5 5 . 7 0}$ \\
Coeffard Deviationt of Variation $(\%)$ & 37 & 28 & 18.55 & $\mathbf{1 8 . 3 9}$ \\
Standard Error & 4.58 & 1.20 & 1.10 & $\mathbf{3 3}$ \\
Lower Bound & 45.52 & 58.30 & 50.14 & $\mathbf{. 8 2}$ \\
Upper Bound & 64.68 & 63.02 & 54.47 & $\mathbf{5 7 . 3 1}$ \\
Minimum & 19 & 24 & 24 & $\mathbf{2 4}$ \\
Maximum & 89 & 94 & 92 & $\mathbf{9 4}$ \\
\hline
\end{tabular}

Source: Extract from SPSS Computed Output, 2017. 
Table 2a: F-test on the significant difference in organizational justice perceptions with respect to workforce hierarchy in teaching hospitals

\begin{tabular}{|lccccccc|}
\hline & Mean Square & F computed & F table & Df & P-value & Chosen Alpha & Remark/Decision \\
Between groups & 4077.987 & 12.62 & 3.00 & 500 & .000 & .05 & Significant/ \\
Within groups & 323.146 & & & & & & Reject $\boldsymbol{H}_{0}$ \\
Total & & & & 502 & & & \\
\hline
\end{tabular}

Source: Extract from SPSS computed output and Statistical Table values, 2017

Table 2b: Duncan test on Organizational Justice and respective management levels

\begin{tabular}{|lccc|}
\hline Staff Cadre & $\mathbf{N}$ & \multicolumn{2}{c|}{ Subset alpha $=\mathbf{0 . 0 5}$} \\
Junior Staff & 252 & $\mathbf{1}$ & $\mathbf{2}$ \\
Top Management & 20 & 52.31 & \\
Senior Staff & 231 & 55.10 & 55.10 \\
Sig & & .032 & 60.66 \\
\hline
\end{tabular}

Source: Extract of SPSS computed output, 2017

Sub-Hypothesis

i. There is a significant difference in distributive justice perception among junior, senior and management staff in Teaching Hospitals.

ii. There is a significant difference in procedural justice perception among junior, senior and management staff in Teaching Hospitals.

iii. There is a significant difference in interactional justice perception among junior, senior and management staff in Teaching Hospitals.

Table 3. F-test on organizational justice dimensions and perception of staff cadre in teaching hospitals.

\begin{tabular}{|lccc|}
\hline Statistics & Distributive & $\begin{array}{c}\text { organizational justice dimensions } \\
\text { Procedural }\end{array}$ & $\begin{array}{c}\text { Interactional } \\
\text { Between Groups }\end{array}$ \\
Within Groups Mean & 219.004 & 1.503 & 38.302 \\
Square & 11.155 & 50.661 & 62.650 \\
F-computed & 19.63 & .030 & 2.208 \\
F-critical & 3.00 & 3.00 & 3.00 \\
Df & 2,500 & 2,500 & 2.500 \\
P-value & .000 & .971 & .111 \\
Chosen Alpha & .05 & .05 & .05 \\
Remark/Decision & Significant/Reject Null & Not Significant/Accept & Not significant/Accept \\
& Hypothesis & null hypothesis & null hypothesis \\
\hline
\end{tabular}

Source: Extract from SPSS Computed Output and Statistical Table values, 2017

From table 1, top management had mean value 55.10, standard deviation value 20.47 and coefficient of variation $37 \%$; senior staff had mean 60.66 , standard deviation 16.84 and coefficient of variation $28 \%$, junior staff had mean 52.31 , standard deviation value 18.55 and coefficient of variation $35 \%$.

Table 2a shows the One Way Analysis of Variance test to ascertain as to whether there was a significant difference in the organizational justice perception among junior, senior and management staff in teaching hospitals. The F-ratio computed statistic 12.62 was greater than F-critical 3.00 with 2 , and 500 degrees of freedom at .05 level of significance ( $F$ computed $=12.62, p<.05)$. Since the F-calculated value is greater than F-critical (F-calculated $12.62>3.00)$, reject the null hypothesis. 
Table $2 \mathrm{~b}$ demonstrated Duncan pairwise comparison test aimed at identifying the independent factors of top management, senior staff and junior staff leading to the significance in the F-ratio computed. From the table, the means for groups in homogeneous subsets are displayed. Junior staff and top management means of 52.31 and 55.10 respectively are in subset 1 while the means of top management and senior staff are in subset 2. In table 3, the F-ratio computed for the significant difference in the distributive justice perception of workers with respect to cadre of staff was F-calculated $19.63>3.00$; procedural justice perception of workforce with respect to cadre of staff was F-calculated $.030<3.000$; interactional justice perception of workforce with respect to cadre of staff was F-calculated $=2.21<$ F-critical 3.000 .

4.2 $\mathrm{Ha}_{2}$ : There is a significant difference in the organizational justice perception among medical doctors, paramedics and supporting staff in teaching hospitals.

Table 4: Descriptive statistics on Organisational justice perceptions of professional category of workforce.

\begin{tabular}{|lcccc|}
\hline \multirow{2}{*}{ Statistics } & Medical Doctors & \multicolumn{2}{c|}{ Category of Workforce } \\
$\mathrm{N}$ & 96 & Paramedics & Supporting Staff & Total \\
Mean & 64.42 & 210 & 197 & $\mathbf{5 0 3}$ \\
Standard Deviation & 16.79 & 55.52 & 51.65 & $\mathbf{5 5 . 7 0}$ \\
Coefficient of Variation (\%) & 26 & 18.28 & 17.86 & $\mathbf{1 8 . 3 9}$ \\
Standard Error & 1.71 & 33 & 36 & $\mathbf{3 3}$ \\
Lower Bound & 61.01 & 53.04 & 1.27 & $\mathbf{. 8 2}$ \\
Upper Bound & 67.82 & 58.01 & 49.14 & $\mathbf{5 4 . 0 9}$ \\
Minimum & 19 & 20 & 54.16 & $\mathbf{5 7 . 3 1}$ \\
Maximum & 94 & 92 & 19 & $\mathbf{1 9}$ \\
\hline
\end{tabular}

Source: Extract from SPSS Computed Output, 2017.

Table 5a: F-test on organizational justice perception with respect to professional groups of workforce in teaching hospitals

\begin{tabular}{|c|c|c|c|c|c|c|c|}
\hline & Mean Square & $\mathrm{F}$ cal & $F$ table & Df & P-value & Chosen Alpha & $\begin{array}{c}\text { Remark } \\
\text { /Decision }\end{array}$ \\
\hline $\begin{array}{l}\text { Between groups } \\
\text { Within aroups }\end{array}$ & $\begin{array}{c}5266.158 \\
318.393\end{array}$ & 16.54 & 3.00 & $\begin{array}{c}2 \\
500\end{array}$ & .000 & .05 & $\begin{array}{c}\text { Significant } \\
\text { Reiect null hypothesis }\end{array}$ \\
\hline Total & & & & 502 & & & \\
\hline
\end{tabular}

Source: Extract from SPSS computed output, 2017

Table 5b: Duncan test on organizational Justice and respective professional groups.

\begin{tabular}{|lccc|}
\hline Professional category & $\mathbf{N}$ & \multicolumn{2}{c|}{ Subset alpha $=\mathbf{0 . 0 5}$} \\
Support Staff & 197 & $\mathbf{1}$ & $\mathbf{2}$ \\
Paramedics & 210 & 51.65 & \\
Doctors & 96 & & \\
Sig & & .062 & 64.42 \\
\hline
\end{tabular}

Source: Extract of SPSS computed output, 2017.

Sub-Hypothesis

i. There is a significant difference in distributive justice perception among medical doctors, paramedics and supporting staff in teaching hospitals.

ii. There is a significant difference in procedural justice perception among medical doctors, paramedics and supporting staff in teaching hospitals.

iii. There is a significant difference in interactional justice perception among medical doctors, paramedics and supporting staff in teaching hospitals 
Table 6. F-test on organizational justice dimensions and perceptions among medical doctors, paramedics and supporting staff in teaching hospitals.

\begin{tabular}{|lccc|}
\hline Statistics & Distributive & $\begin{array}{c}\text { Organizational Justice Dimensions } \\
\text { Procedural }\end{array}$ & Interactional \\
Between Groups & 192.957 & 263.918 & 102.908 \\
Within Groups Mean & 11.259 & 49.612 & 62.792 \\
Square & 17.138 & 5.320 & 1.639 \\
F-calculated & 3.00 & 3.00 & 3.00 \\
F-critical & 2,500 & 2,500 & 2.500 \\
Df & .000 & .005 & .195 \\
P-value & .05 & .05 & .05 \\
Chosen Alpha & $\begin{array}{c}\text { Significant/Reject the null } \\
\text { Hypothesis }\end{array}$ & $\begin{array}{c}\text { Significant/Reject the null } \\
\text { hypothesis }\end{array}$ & $\begin{array}{c}\text { Not significant/ Accept } \\
\text { null hypothesis }\end{array}$ \\
\hline
\end{tabular}

Source: Extract from SPSS computed output, 2017

From table 4, medical doctors had mean value 64.42, standard deviation value 16.79 and coefficient of variation $26 \%$; paramedics had mean 55.52 , standard deviation 18.28 and coefficient of variation $33 \%$; supporting staff had mean 51.65 , standard deviation value 17.86 and coefficient of variation $36 \%$.

Table $5 a$ shows the One Way Analysis of Variance test to ascertain as to whether there was a significant difference in the organizational justice perception of the workforce of teaching hospitals on the basis of various professional groups of employees. The F-ratio computed statistic 16.54 was greater than F-critical 3.00 with 2, and 500 degrees of freedom at .05 level of significance (F computed $=16.54, p<.05)$. Since the F-calculated value is greater than F-critical (F-calculated $16.54>\mathrm{F}$ critical 3.00 ), reject the null hypothesis.

Table $5 \mathrm{~b}$ demonstrated Duncan pairwise comparison test aimed at identifying the independent factors of medical doctors, paramedics and supporting staff leading to the significance in the F-ratio computed. From the table, the means for groups in homogeneous subsets are displayed. Paramedics and supporting staff had means of 55.52 and 51.65 respectively are in subset 1 while the mean of medical doctors is in subset 2. In table 6, the F-ratio computed for the significant difference in the distributive justice perception of workers with respect to professional groups of staff was F-calculated 17.14> 3.00; procedural justice perception of workforce with respect to professional groups of staff was F-calculated $.5 .32>3.000$; interactional justice perception of workforce with respect to professional groups of staff was $\mathrm{F}$ calculated $1.64=<$ F-critical 3.000 .

4.3 $\mathrm{Ha}_{3}$ : There is a significant effect of organizational justice dimensions on turnover intentions of workers in university teaching hospitals

Table7. Multiple Regression Analysis on Organizational Justice Dimensions and Turnover Intention

\begin{tabular}{|c|c|c|c|c|c|c|}
\hline Variables & $\begin{array}{c}\text { Coefficients } \\
(\boldsymbol{\beta})\end{array}$ & SE & $\mathbf{t}$ & $\begin{array}{c}\mathbf{P} \\
\text { Value }\end{array}$ & $\begin{array}{c}\text { Alpha } \\
(\alpha)\end{array}$ & Remarks \\
\hline Turnover Intention(TI) & 8.873 & 0.773 & 11.466 & 0.0000 & 0.05 & \\
\hline Distributive justice (DJ) & 0.027 & 0.018 & 1.504 & 0.133 & 0.05 & $\mathrm{P}>\alpha \quad \mathrm{ns}$ \\
\hline Procedural Justice (PJ) & -0.001 & 0.019 & -0.031 & 0.978 & 0.05 & $\mathrm{P}>\alpha \quad \mathrm{ns}$ \\
\hline Interactional Justice(IJ) & -0.011 & 0.038 & -0.278 & 0.781 & 0.05 & $\mathrm{P}>\alpha \quad \mathrm{ns}$ \\
\hline $\begin{array}{ll}\mathrm{F} & =0.772 \\
\mathrm{~F}(\text { Prob }) & =0.510 \\
\mathrm{R}^{2}= & 0.004 \\
\text { Adj } R^{2} & =-0.001 \\
\mathrm{WD} & =0.772\end{array}$ & & & & & & \\
\hline
\end{tabular}

Source: Computed output from Eviews Version 3.0 
Table 7 displays the multiple regression analysis of distributive justice (DJ), interactional justice (IJ) and procedural justice (PJ) on turnover intention (IT). The t test statistic shows that distributive justice had non-significant positive effect on turnover intention $(t=1.50, p>.05)$; interactional justice had non-significant negative effect on turnover intention $(t=-0.27, p>.05)$; procedural justice had non-significant negative effect on turnover intention $(t=-0.03, p>.05)$. The t test results imply that distributive justice in health institutions does not in any way reduce the intent of health workers to leave their entities in Nigeria. However, the results further imply that interactional justice and procedural justice are not good predictors of the turnover intent but stem the desire and deliberate will of employees to leave teaching hospitals. The beta coefficients for of explanatory variables of distributive justice, interactional justice and procedural justice were $\beta=0.02, \beta=-0.01$ and $\beta=-0.0006$ respectively. The coefficients indicate the level of contribution of each predictor variable to turnover intention in teaching hospitals. The second partition of table 7 demonstrates that $R^{2}=0.004$, Adjusted $R^{2}=-0.0013$ and $F$ statistic $=0.77$. From the $F$ statistic computed, the result suggests that there is significant relationship between the tripartite dimension of organizational justice and turnover intentions. $(F=0.77, p>0.05)$.

\section{Discussion and Conclusion}

The descriptive analysis was to establish the difference in organizational justice perception among junior, senior and management staff in teaching hospitals in Nigeria. From table 1, the responses on the average indicated that senior staff had the highest mean value of 60.66 while junior staff had the lowest mean value of 52.31. The statistics suggested that top management and senior staff evaluated the fairness of the entities over and above the junior staff in their sense of judgment. This result demonstrated that the perception of organizational justice among the three levels of workforce in teaching hospitals differed. Furthermore, the standard deviation value for top management was 20.47, senior staff was 16.84 and junior staff was 18.55. This showed the dispersion of organizational justice distribution as against the various levels of workforce. The result suggested the diversity of opinion at each given level of staff hierarchy in absolute terms. In relative terms, the co-efficient of variation statistic was considered. The difference in organizational justice perception between top management $37 \%$ and junior staff $35 \%$ was close vis-à-vis the senior staff of $28 \%$. The result clearly showed that organizational justice perception of workforce in teaching hospitals in comparison with the various levels of management varied.

From table $2 \mathrm{a}, \mathrm{F}$ ratio computed was 12.63 as against the $\mathrm{F}$ critical of 3.00 with 2 and 500 degrees of freedom at .05 chosen alpha $\left(F_{(2,500)}=12.62, p<.05\right)$. The result indicated that there was a significant difference in the perception of organizational justice with respect to the independent factors of top management, senior staff and junior staff in university teaching hospitals in Nigeria. Furthermore, Duncan post hoc analysis was computed to ascertain the group(s) of staff cadre resulting in the significant difference in the organizational justice perception of the workforce in teaching hospitals. In table $2 \mathrm{~b}$, the means for groups in homogeneous subjects were displayed. Junior staff and top management had mean values of 52.31 and 55.10 respectively in subset one while the mean values of top management 55.10 and senior staff 60.66 were in subset two. The result clearly demonstrated that junior staff and senor staff categories were in different subsets giving rise to the statistically significant difference in the perception of organizational justice among workers in teaching hospitals. The senior staff and junior staff of medical and non-medical workforce in separate subsets suggested that they were at variance in their sense of judgment over the fairness and justice of teaching hospitals in Nigeria.

Besides, sub-hypotheses were tested on the basis of the three dimensions of organizational justice and their levels of workforce in the teaching hospitals. From table 3 , the statistics indicated that there was a significant difference in the distributive justice perception of workers with respect to top management, senior staff and junior staff $\left(F_{(2,500)}=19.63, P<.05\right)$; there was no significant difference in procedural justice perception of workforce with respect to top management, senior staff and junior staff $\left(F_{(2,500)}=.030, P>.05\right)$; there was no significant difference in interactional justice perception of workforce with respect to top management, senior staff and junior staff in teaching hospitals in Nigeria $\left(F_{(2,500)}=2.21, P>.05\right)$. The result suggested that the three categories 
of workforce on the basis of hierarchy to some extent had similar perceptions in the organizational justice dimension of procedural and interactional fairness but distributive justice perception of the workforce hierarchy which could be attributed to the operation of dual salary scale and discrimination in the payment of allowances in university teaching hospitals in Nigeria.

The finding of the study is compatible with that of Hatam, Fardid and Kovosi (2013) who found that there was a significant difference in organizational justice perception of nurses between general and specialty hospitals. The scholars also found that there was a significant difference in organizational justice perception of nurses with respect to different wards in hospitals. From the separate dimensions of organizational justice perceptions, there were some discrepancies in the findings. Procedural and interactional justice of three levels of management was not statistically significant as against the findings of Hatam et al. These disagreements in findings were attributable to the various groups considered. The current study considered the groups on the basis of organizational hierarchy involving different class of workers while the work of Hatam et al considered nurses to the exclusion of other category of workers and grouped nurses on the basis of various wards. Besides, the studies were conducted in different countries, though in similar sectors.

In view of the second objective and hypothesis, the analysis of the responses from table 4 on the average demonstrated that medical doctors had the highest mean of 64.42 while the supporting staff had the lowest mean of 51.65. The mean values observed suggested that medical doctors and paramedics rated the fairness of university teaching hospitals higher than the supporting staff in their sense of judgment. Undoubtedly, the perception of organizational justice among the three professional groups stood apart in university teaching hospitals. Furthermore, the standard deviation for medical doctors was 16.79 , paramedic was 18.28 and supporting staff was 17.8 . In absolute terms, the standard deviation statistics displayed the variability of the organizational justice of the workforce on the three professional grouping as indicated by the statistics. In relative terms, the differences in the organizational justice perception between supporting staff $36 \%$ and paramedics $33 \%$ was closer vis 'a vis the medical doctors of $26 \%$. The result further affirmed that the organizational justice perception of workers in teaching hospitals of various professional groups varied substantially.

From table $5 \mathrm{a}$, the $\mathrm{F}$ ratio computed was 16.54 compared to the $\mathrm{F}$ critical of 3.00 with 2 and 500 degrees of freedom at .05 chosen alpha $\left(F_{(2,500)}=16.54, P<.05\right)$. The result showed that there was a significant difference in organizational justice perception with respect to various professional groups of workforce in university teaching hospitals of Nigeria. In addition, Duncan post hoc test was applied with a view to identifying the independent factors of medical doctors, paramedics and supporting staff group resulting in the statistically significant difference of the Fratio computed. In table $5 \mathrm{~b}$, the mean statistics for paramedics and supporting staff was 55.52 and 51.65 respectively and the mean values were exclusively in subset one while the mean statistic for medical doctors was 64.42 and was in subset two. The results suggested that the organizational justice perception of paramedics and supporting staff was quite close and homogeneous but medical doctors leading to the statistically significant difference and rejection of the null hypothesis postulated. Moreover, sub hypotheses were further subjected to F-test on the basis of the distributive, procedural and interactional dimension of organizational justice among workforce of professional groups. From table 6, the statistics indicated that there was a significant difference in the distributive justice perception of workers with respect to professional categories of medical doctors, paramedics and supporting staff $\left(\mathrm{F}_{(2,500)}=17.14, \mathrm{P}<.05\right)$ and there was significant difference in the procedural justice perception of medical doctors, paramedics and supporting $\operatorname{staff}\left(F_{(2,500)}=5.32, P<.05\right.$ and there was no significant difference in interactional justice perception of medical doctors, paramedics and supporting staff. The result suggested that the perceptions of the staff categories of distributive and procedural justice varied substantially. This further meant that the procedures leading to organizational outcomes and the rewards distributed to the various categories of workers were of serious concern. The diversity of procedural and distributive justice perceptions were possible reasons for bickering noticeable among different professional groups and unions in the medical subsector.

The finding of the present study is concordant with of Mohamed (2014) who found that there was a significant difference in distributive and procedural justice perception with respect to nurses 
and doctors while there was no significant difference in interactional justice perception between nurses and doctors.

From table 7, the study found distributive justice had non-significant positive effect on turnover intention ( $t=1.50, p>.05)$; interactional justice had non-significant negative effect on turnover intention ( $t=-0.27, p>.05)$ while procedural justice had non-significant negative effect on turnover intention ( $t=-0.03, p>.05)$. The findings of the current study are not totally consistent with works of Rahim et al (2001) and Lee (2000) who found that distributive, procedural and interactional justice had significant effect on turnover intentions; distributive justice had significant negative effect on turnover intention and procedural had significant positive effect on turnover intentions. The variations in the findings are the areas of direction and statistical significance, which may be attributable to diversity in location and economic subsectors of Nigeria and United States of America in which the studies were conducted. The stage of economic development of the two countries is not similar giving rise to different attitudinal responses to matters of turnover.

\section{Implications for Theory and Practice}

The findings from the study contributed to theoretical foundations and management practice among workers in university teaching hospitals. The study provides empirical evidence to underpin theories of equity (Adams, 1965), procedural preference model (Leventhal, 1976) and distributive justice theory (Deutsch, 1975). However, the findings also demonstrated the inadequacy of the equity theory of Adams because the theory examines fairness only on the basis of distributing organizational outcomes to the exclusion of fairness in procedures guiding the decision making process and fairness in the interpersonal interactions among members of entities. From the available literature, there is paucity of empirical evidence in the context of the research settings and health sector in Nigeria. Thus, the study contributed to the existing body of knowledge. The findings had implications for managerial practice in overseeing university teaching hospitals in Nigeria. Medical directors, ministers of and commissioners for the industry are to consider organizational justice as a critical element in the formulation and implementation of policy framework considering the bickering and advocacy for equality among various professional groups and labor unions in the public health care institutions.

In addition, we proffer recommendations for medical directors, administrators, paramedics, physicians and regulatory agencies of university teaching hospitals to fashion out non discriminating policy framework and implement them consistently across all categories of workers devoid of bias to promote genial work atmosphere in health care institutions. It is further recommended that Federal and State Ministries of Health should enact laws through the legislative arm of government to regulate the proliferation of unions that breed professional dichotomy, discrimination and prejudice among medical doctors, paramedics and supporting staff in teaching hospitals. We want to recommend that the Federal and State Ministries of Health should also review and adopt a unified salary structure as against the existing dual salary scale which has become a contentious issue in the health sector leading to incessant strikes.

\section{Limitations and Future Research Direction}

There are limitations despite the findings and implications of the study. The data collection was restricted to university teaching hospital as against all public health institutions in the country for better generalization of the findings. Besides, the study considered organizational justice and turnover intention as the only work related attitude aside others. Methodologically, the study is quantitative bias and can adopt mixed methods with a view to providing a wider spectrum of perspectives. Furthermore, the design of the current study was analytic descriptive survey which has inherent shortcomings. 


\section{References}

Adams, S. J. (1965). Inequity in Social Exchange. In L. Berkowitz (Ed.), Advances in Experimental Social Psychology, 2, (267-299), New York: Academic Press.

Ary, D; Jacobs, C L; Razavieh A \& Sorensen C. (2006). Introduction to Research in Education

(7 th ed.).Canada, Thomson Wadsworth.

Ayobami P.A.\& Eugene O.O. (2013). Impact of Perceived Organizational Justice on Organizational Commitment of a Food and Beverage Firm in Nigeria. International Journal of Humanities and Social Sciences, 3(14), 4: $207-218$.

Baldwin S (2006). Organizational Justice, Brighton; Institute for Employment Studies

Bies, R.J., \& Moag, J.S. (1986). Interactional justice: Communication criteria of fairness. In R.J. Lewicki, B.H. Sheppard and B.H. Bazerman (Eds.), Research on Negotiation in Organizations ( 43-55). Greenwich, CT: JAI Press.

Blakely, G. L., Andrews, M. C., \& R. H. Moorman. (2005). The Moderating Effects of Sensitivity on The Relationship between Organizational Justice and Organizational Citizenship Behaviors. Journal of Business and Psychology, 20(2), 259-273.

Bowen, D. E., Gillil S. W \& Folger, R. (1999). Human Resources Management and Service Fairness: How Being Fair with Employees Spills over to Customers. Organizational Dynamics, 27, 129-135

Cochran, W. G. (1963). Sampling Techniques, (2nd ed.), New York: John Wiley and Sons, Inc.

Coetzee, M. (2005). The fairness of affirmative action: An organizational perspective. Unpublished Doctorial Thesis, University of Pretoria, Pretoria

Colquitt, J. A., \& J. M. Chertkoff. (2000). Explaining Injustice: The Interactive Effect of Explanation and Outcome on Fairness Perceptions and Task Motivation. Journal of Management, 28(5), 591-610.

Colquitt, J. A. (2001). On the dimensionality of organizational justice: A construct validation of a measure. Journal of Applied Psychology 86 (3), 425-445.

Colquitt, Jason A., Conlon, Donald E., Wesson, Michael J., Porter, Christopher 0. L. H., \& Yee Ng, K. (2001). Justice at the millennium: A meta-analytic review of 25 years of organizational justice research. Journal of Applied Psychology86 (3),. 425-445

Cooper D. R \& Schindler P. S (2009). Business Research Methods (9 th ed.). New Delhi,

Davoudi S.M and Fartash K (2013). Turnover Intetions: Iranian employees, SCMS Journal of Indian Management, 10 (1), 89-99 McGraw Hill.

Deutsch, M. (1975). Equity, Equality, and Need: What Determines Which Value Will Be Used as the Basis of Distributive Justice? Journal of Social Issues, 31,(3), 137-149

Eves F, Giilean G.M. \& Celik S. (2014). Primary School Teachers' Perceptions of Justice and Trust in Principals in Ankara, Turkey. American International Journal of Contemporary Research, 4 (2), 33-41.

FitzGerald, M. R. (2002). Organizational Cynicism: Its Relationship to Perceived Organizational Injustice and Explanatory Style. University of Cincinnati, UMI Microfilmed 2002, 1-70.

Francis A (2004). Business Mathematics and Statistics (6th ed.). United Kingdom, Thompson Learning.

Gefen, D., Ragowsky, A., \& C. Ridings. (2008). Leadership and Justice: Increasing non-Participating Users' Assessment of an IT Through Passive Participation. Information \& Management, 45, 507-512.

George . J. M \& Jones G. R (2006). Contemporary Management. Boston, McGrawHill

Greenberg J (2012). Organizational Behavior. NewJersey. Prentice Hall

Hatam N; Fardid M \& Kavosi (2013). Perceptions of Organizational Justice among Nurses working in University Hospitals of Shiraz: A comparison Between general and Specialty Settings. Nurses Midwifery Study 2(4): 77-82.

Karriker, J. H., \& M. L. Williams. (2009). Organizational Justice and Organizational Citizenship Behavior: A Mediated Multifoci Model. Journal of Management, 35(1), 112-135.

Konowsky, M. A. (2000). Understanding Procedural Justice and Its Impact on Business Organizations, Journal of Management, 26(3), 489-511

Lee H. (2000). An Empirical Study of Organizational Justice as a Mediator of the Relationship among LeaderMember Exchange and Job Satisfaction, Organizational Commitment and Turnover Intention, Unpublished PhD Thesis Submitted to Faculty of the Virginia Polytechnic Institute and State University, Black-burg, Virginia.

Leventhal, G. S.( 1976). The distribution of reward and resources in groups and organizations. Advanced Experimental Social Psychology, 9: 91-131.

Levine D. M; Stephen D F; Krehbiel T C \& Berenson M. M (2008). Statistics for Managers: Using Microsoft Excel. Upper Saddle River, Pearson Prentice Hall

Mohamed. A.S.(2014). The Relationship between Organizational Justice and Quality Performance among Healthcare Workers: A Pilot Study. The Scientific World Journal 3(4), 1-7. 
Nadiri H. \& Tanov C. (2009).An Investigation of the Role of Justice in Turnover Intentions, Job Satisfaction and Organizational Citizenship Behavior in Hospitality Industry. International Journal of Hospitality Management, 29 (2010) 33-41

Nirmala, M. C., \& K. B. Akhilesh. (2006). An attempt to Redefine Organizational Justice: in the Rightsizing Environment. Journal of Organizational Change Management, 19(2), 136-153.

Nunnally. J. (1978). Psychometric Theory. New York, NY: McGrawHill

Nwankwo, O. C (2006). A Practical Guide to Research Writing for Students in Education and Social Sciences. Port Harcourt, Pam Unique Publishers

Olajide T A, Asuzu C M \& Obembe A T (2015) Doctor-Nurse Conflict in Nigeria Hospitals: Causes and Modes of Expression, British Journal medicine and Medical Research 9 (10): 1-12.

Oleribe O O , Ezime P I et al (2016) Industrial Action by Health Care Workers in Nigeria in 2003-2015, an inquiry into causes, consequences and control- a cross sectional descriptive study, Human Resources for Health 14: 1-10

Oluwafemi O.J. (2013). Predictors of Turnover Intentions among Employees in Nigeria's Oil Industry. Organizations and Markets in Emerging Economies 4, 2(8): 2029-4581.

Osakede K O \& ljimakinwa S A (2014) The Effect Public Sector Health Care Workers strike: Nigerian Experience, Review of Public Administration and Management 3(6): 154-161.

Owolabi A.B (2012). Effect of Organizational Justice and Organizational Environment on Turnover Intention of Health Workers in Ekiti State, Nigeria. Research in World Economy, 3(1), 3: 28 - 34.

Podsakoff. P .M; Mackenzie S. B; Moorman R. H and Fetter R(1990). Transformational Leadership Behaviors and their Effects on Followers' Trust in Leader, Satisfaction and Organizational citizenship Behavior. The Leadership Quarterly 1(2), 107-142.

Rahim A. M; Magner R. N; Antonioni . D \& Rahaman S (2001). Do Justice Relationships with OrganisationDirected Reactions differ across U. S and Bangladash Employees? The International Journal of Conflict management, 12(4): 333-349.

Rastgar, A.A and Pourebrahimi N (2013) .A Study of the Relationship between Organisational Justice and Turnover Intentions: Evidence from Iran, International Journal of Research in Organisational Behaviour and Human Resources Management 1 (2); 1-10.

Roodt, G. (2004). Turnover Intentions. Unpublished Document. Johannesburg: University of Johannesburg.

Saunders M; Lewis P \& Thornhill A (2007). Research Methods for Business Students (4th ed.). England, Pearson Education limited

Udechukwu I, Harington W, Maryak T, Segal S \& Graham S (2007). The Georgia Department of Corrections: An Exploration Reflection on Correctional Turnover and its Correlates, Public Personnel Management 36 (3), $36-45$.

Thibault, J., and Walker, L. (1975). Procedural justice: A psychological analysis. Hillsdale, NJ: Lawrence Erlbaum associates.

Wadi, R. A. L (2007). Organizational Justice: An Empirical Study on Palestinian Ministarian of the Gaza Strip. Journal of Business Research. University of Sohag, Egypt, 21(1),23-30. 